\title{
ASOCIACIONISMO Y REPRESENTACIÓN DE INTERESES MÉDICOS EN BUENOS AIRES, 1852-1880
}

\author{
Ricardo González Leandri \\ Departamento de Historia de América - Centro de Estudios Históricos. CSIC \\ Duque de Medinaceli, 6 - Madrid (España) 1
}

\section{RESUMEN}

El presente artículo analiza el surgimiento de las primeras asociaciones médicas de Buenos Aires entre 1852 y 1880 . La primera, la Asociación Médica Bonaerense, se caracterizó por su ambivalencia frente al elitismo de los catedráticos de la Facultad de Medicina. Tras su declive, consecuencia de la creación de la Academia de Medicina de Buenos Aires, el impulso asociativo fue retomado por el Círculo Médico Argentino, que recuperó su faceta más impugnadora e intentó aunar los intereses de estudiantes y profesores jóvenes.

\section{SUMMARY}

This paper discusses the first medical associations in Buenos Aires, between 1852 and 1880 . The main characteristic of the very first association, the Asociación Médica Bonaerense, was its ambivalent atitude in regards to doctor's and professor's elitism. Following the decline of this association, due to the creation of the Academia de Medicina de Buenos Aires, its more pugnacious facet was retaken by the Círculo Médico Argentino, who attempted to unite both students and young teacher's interests aims.

\section{SECTORES PROFESIONALES Y ESTRATEGIAS ASOCIACIONISTAS}

El presente artículo describe los inicios del asociacionismo científico y profesional en Buenos Aires en la segunda mitad del siglo XIX. Centra para ello su atención en el caso específico del cuerpo médico.

1 Este artículo forma parte de un proyecto de investigación más amplio, financiado por la Dirección General de Investigación de la Consejería de Educación y Cultura de la Comunidad de Madrid, que estudia los intercambios de ideas e iniciativas institucionales entre los colectivos médicos español y argentino en el siglo XIX y principios del XX. 


\section{RICARDO GONZÁLEZ LEANDRI}

Conviene destacar, en tal sentido, que los intentos asociativos de los médicos de Buenos Aires, junto a su pugna por la obtención de un monopolio cognitivo, formaron parte indisoluble del vasto proceso de profesionalización médica que se dio en Buenos Aires en dicho período y que actuó, a su vez, como eje de la constitución de un campo específico del arte de curar ${ }^{2}$.

En una primera instancia es necesario dejar claro que las estrategias asociacionistas tuvieron históricamente tanta relevancia para el éxito de los grupos ocupacionales deseosos de convertirse en profesiones, que muchos autores han tendido a identificarlas con el mismo proceso de profesionalización. Es esta una orientación típica de aquellas historias encaradas por miembros del propio cuerpo profesional, en nuestro caso los médicos, especialmente en aquellos países cuyo proceso de profesionalización fue inducido por el surgimiento de sólidas asociaciones ${ }^{3}$.

Es innegable que un proceso tan complejo no es reductible a su mera expresión asociativa. Sin embargo, sin fusionar un proceso con otro y, sobre todo, sin intentar establecer etapas "necesarias", es válido considerar que el tipo y grado de asociaciones producido por un grupo ocupacional en su trayecto hacia la profesionalización es un importante indicio de su grado de madurez, medido precisamente a través de su capacidad de establecer lazos institucionales.

En segundo lugar debe también tenerse en cuenta que el asociacionismo, unido al desarrollo de saberes científicos, es un tema de abordaje arduo, dado que por sus propias características, sobre todo en sus etapas iniciales, tiende a poner en contacto realidades y experiencias muy diversas: proyectos científicos, ansias de distinción, búsqueda de reconocimiento, procesos de jerarquización, intentos de disminuir posiciones marginales, etc. Tal diversidad de opciones, y la existencia de problemáticas distintas y hasta contradictorias en su evolución, es un hecho común en la historia de estos movimientos en los diversos campos. Esto dio pie, en forma obvia, a la existencia de distintas interpretaciones y corrientes teóricas entre los que investigaron el tema ${ }^{4}$. Autores como Habermas y Foucault, a pesar de sus opuestos puntos de vista

2 Al hablar de un campo -literario, científico, deportivo, etc- hacemos referencia, siguiendo a Pierre Bourdieu, a la constitución de un sistema de instituciones y agentes directa o indirectamente relacionados con la existencia de una actividad. BOURDIEU, P. (1988), Cosas dichas, Gedisa, Buenos Aires; BOURDIEU, P. (1995), Las Reglas del Arte, Anagrama, Madrid; BoURDIEU P. (1985), "The genesis of the concepts of "habitus" and "field"", Sociocriticism, 2, p. 11-24.

3 Se destacan en tal sentido los producidos en Inglaterra y EE.UU. donde la existencia de las poderosas British Medical Association y American Medical Association fue determinante. La críticas más sólidas a esta orientación pueden consultarse en JOHNSON, T. (1972), Professions and Power, MacMillan, Londres, Freidson, E. (1970), Profession of Medicine. A Study in the Sociology of Applied Knowledge, Harper and Row, New York y (1986), Professional Powers. A Study of Institucionalization of Formal Knowledge, University of Chicago Presss, Chicago and London.

4 Una importante línea de análisis que va desde Tocqueville hasta Habermas destaca del asociacionismo su fuerte centralidad social. Este último autor considera que las asociaciones cívicas, dentro de las 
coinciden, sin embargo, en un punto fundamental: la crucial vinculación que detectan entre el surgimiento de tales asociaciones y la constitución de una sociedad civil, ya sea para alabar su virtualidad democrática, como para señalar su potencialidad de controls.

Sin embargo, a pesar de que el tipo de análisis propuesto por ambos autores es útil como orientación general, hay, sin embargo, ciertas cuestiones vinculadas de forma más estrecha al asociacionismo profesional que requieren la adopción de planteamientos más específicos.

Debe destacarse para ello, en la medida que la información disponible lo permita, determinados aspectos del propio funcionamiento interno de las asociaciones, como los procesos de jerarquización interna, los de conformación de sus élites dirigentes, y los de inclusión y exclusión. Como trasfondo de esos procesos es importante tener también presente las características específicas del vínculo que se establece entre las estrategias asociacionistas y la definición de un "proyecto profesional", destacando el hecho de que la estructura adquirida por una profesión es el resultado de la acción combinada del esfuerzo dirigido a generar un mercado, de las acciones y gestos tendentes al logro de prestigio social y de las solicitudes de protección estatal. Todos estos procesos implican un fenómeno colectivo, dado que sus logros sólo pueden ser obtenidos mediante un importante esfuerzo de organización ${ }^{6}$.

Sin dejar de destacar el valor de las asociaciones como elementos fuertemente persuasivos sobre determinados estamentos, ajenos pero imprescindibles para todo grupo que desee convertirse en una profesión, pretendemos, en este caso particular, hacer hincapié en la ambigua invocacion médica a la construcción comunitaria, característica de la situación heterogénea del incipiente campo del arte de curar en el Buenos Aires de entonces.

\footnotetext{
cuales las de carácter profesional ocupan un lugar relevante, son elementos decisivos para la conformación de una sociedad civil burguesa y de una amplia "esfera pública" dado que producen transformaciones profundas en la sociabilidad y en las prácticas comunicativas.Tales transformaciones, que se traducen en el incremento de la densidad y complejidad de los lazos sociales, inducen a Habermas a considerarlas como la fuente misma de la formación de la ciudadanía. Otras perspectivas no son en cambio tan optimistas y tienden a enfatizar, en referencia al mismo proceso, cuestiones de otra índole. Foucault, por ejemplo, visualiza a la vida asociativa colaborando activamente en la formación de un sistema de control social. Destaca en tal sentido las formas micro-sociales de vigilancia que muchas asociaciones implican. TOCQueville, A. (1984), La Democracia en América, Alianza, Madrid; HABERMAS, J. (1994), Historia y Crítica de la opinión pública, Gustavo Gilli, Barcelona; FOUCAULT, M. (1979), Microfisica del poder, La Piqueta, Madrid. Consúltese también, GoldSTEIN J. (1984), "Foucault among the Sociologists. The "Disciplines" and the History of the Professions", History and Theory, 22, (2), p. 170-192..

5 Muchas de estas coincidencias son señaladas por FORMENT C. (1995), en "The Formation of Civil Society in Perú: ¿Democratic or Carcelary?”. Ponencia preparada para la conferencia "Democracy and Citizenship in Latin America" Social Science Research Council, Bogotá, August, (mimeo).

6 SARfatti LaRson, M. (1979) The Rise of Professionalism. A Sociological Analysis, University of California Press, Berkeley.
} 


\section{RICARDO GONZÁLEZ LEANDRI}

\section{LAS ASOCIACIONES MÉDICAS DE BUENOS AIRES ENTRE 1852 Y 1870.}

\section{La Asociación Médica Bonaerense.}

Con la caída de Rosas la sociedad de Buenos Aires comenzó a experimentar un nuevo clima social y político, producto del entusiasmo de las élites triunfantes. Como consecuencia de ello se encararon de inmediato, aunque con éxito desigual, reformas institucionales tendentes a promover la adaptación del país a la nueva realidad política y, sobre todo, socioeconómica que se vislumbraba.

Una de aquellas primeras medidas estuvo destinada a reglamentar y a impulsar el funcionamiento del cuerpo médico dividiéndolo en tres secciones: Facultad de Medicina, Consejo de Higiene y Academia. Dado que la Academia casi no llegó a funcionar durante estos años y que el Consejo de Higiene encontró serias dificultades para realizar una actividad coherente, la recreación de la Facultad de Medicina y, sobre todo, el caracter autónomo de otras instancias universitarias que se le otorgó fue la cuestión médico-institucional más sobresaliente de estos primeros años7.

Dichas medidas, en principio bastante limitadas, actuaron como fuente de legitimación de los médicos diplomados. Puede considerárselas, por lo tanto, como el primer intento del Estado provincial de definir áreas de intervención y como expresión de los intereses de una pequeña élite de médicos notables con fácil acceso a las altas esferas del poder, que a partir de entonces se cristalizó en la cúspide.

La élite médica diplomada del periodo estaba constituida por aquellos "notables", que detentaban las cátedras de la facultad, monopolizaban los más apetecibles cargos públicos y disponían, sobre todo por su elevada extracción social, de importantes clientelas. Debajo de ellos se situaban los "otros médicos" sector muy heterogéneo que nucleaba a un vasto conjunto de aspirantes a la élite y de desplazados, por múltiples motivos, de los canales más importantes de acceso a las redes de influencia y a los recursos.

A su vez, la élite diplomada, sobre todo en sus estamentos más bajos, competía dentro del difuso campo del arte de curar - a veces con notoria desventaja - con una gama muy extensa de otros curadores que incluía a los homeópatas, a los médicos extranjeros sin título reconocido, a las curanderas y curanderos y a los farmacéuticos ${ }^{8}$.

Teniendo en cuenta esta realidad, puede constatarse el papel importante que jugaron en dicho período los afanes médicos por definir un área de incumbencias propia,

\footnotetext{
7 CANTón, E. (1928), Historia de la Medicina en el Río de la Plata, 4, Hernandez y Galo Sáez, Madrid; HALPERÍN DONGHI, T. (1962), Historia de la Universidad de Buenos Aires, Eudeba, Buenos Aires.

8 Un análisis del campo del arte de curar en Buenos Aires durante este período puede consultarse en GONZÁLEZ LEANDRI (1997) "La profesión médica en Buenos Aires, 1852-1870", pp. 21-53. En: Lobato, M. Política, médicos y enfermedades. Lecturas de Historia de la Salud en la Argentina, Biblos/HISA, Buenos Aires.
} 
por consolidar instituciones autónomas a partir del apoyo estatal y por ver garantizada su posición como grupo legalmente privilegiado que le permitiera excluir o incluir en forma subordinada a muchos de sus competidores dentro de lo que pretendían definir como práctica legítima. En ello jugó un importante papel el asociacionismo, que como expresión bastante general de los "otros médicos" emergió por esas fechas.

En tal sentido puede afirmarse que un cambio cualitativo tuvo lugar en el proceso de profesionalización médica cuando en 1860 un grupo recién egresado de la Facultad de Medicina decidió impulsar la creación de la Asociación Médica Bonaerense9. Debe destacarse, teniendo en cuenta los avatares y pugnas propios del campo del arte de curar, que dicha asociación tuvo un importante antecedente en la Sociedad de Farmacia, cuyos directivos destacaban de manera frecuente su carácter de única "corporación científica" del país ${ }^{10}$. Dentro del ámbito específico de los médicos puede apreciarse que si bien otros nucleamientos de características parecidas fueron fundados durante este período, la Asociación Medica Bonaerense fue la única que, combinando los roles de impulsora de reuniones científicas y defensora de los intereses profesionales de los médicos, llegó a tener una vida relativamente prolongada.

La creación de tales asociaciones en aquellos precisos momentos coincidió, a su vez, con una oleada asociativa señalada por distintos investigadores, que tenía como principal escenario a determinados países europeos y a la cual comenzaban a sumarse también otros de América Latina, de incipiente transformación en sus estructuras sociales ${ }^{11}$.

Algunos autores, que se han ocupado de forma más teórica de las condiciones a partir de las cuales es posible que emerjan asociaciones, han puesto especial énfasis en lo que Stinchcombe denominó "tecnología social disponible" que se refiere fundamentalmente a las condiciones económicas y técnicas que determinan qué recursos se encuentran disponibles para los creadores de nuevas organizaciones. Tal concepto intenta relacionar la capacidad asociativa de una sociedad en un momento dado con ciertas variables sociales básicas que tienen un efecto positivo sobre las posibilidades de éxito de las nuevas formas organizativas y fundamentalmente sobre las motivaciones para fundarlas. Dicho esquema fue complejizado por Sarfatti Larson quien vio

\footnotetext{
9 Una útil reseña de la fundación de la Asociación Médica Bonaerense se halla incluida en "Asociación médica Bonaerense", Revista Médico-Quirúrgica (1868), Año 5, nº 3, 8 de mayo, p. 38-40.

10 La Asociación Farmacéutica de Buenos Aires fue fundada en el año 1856. Reconocida legalmente por el gobierno en 1858, cambió su nombre por el de Sociedad de Farmacia Nacional Argentina en 1863. "Introducción", Revista Farmacéutica (1860), año 1, tomo 1, octubre 1.

11 Carlos Forment registra tal fenómeno para el Perú en el que destaca que entre los años 1850 y 1876 se duplicó cada diez años el número de sus asociaciones. En Argentina, fundamentalmente en Buenos Aires, sucedió un fenómeno similar. FoRMENT, C. (1995).
} 


\section{RICARDO GONZÁLEZ LEANDRI}

la necesidad de incluir también variables de tipo ideológico, que a la vez que limitan las alternativas disponibles o imaginarias, determinan las motivaciones para organizar ${ }^{12}$.

En el caso del estudio de las asociaciones médicas de Buenos Aires en la década de 1860 , tales precisiones son muy importantes, dado que en el momento de los primeros intentos asociativos no se habían registrado aún transformaciones de crucial importancia en ninguna de las grandes variables sociales, a pesar de que una cierta prosperidad y el proceso de urbanización comenzaban a hacerse notar de manera creciente.

Puede pensarse, de tal manera, que el asociacionismo médico de Buenos Aires estuvo influido en sus inicios sobre todo por motivos de tipo ideológico, entre los que destacaba una visión optimista del desarrollo futuro de la sociedad, y se vio favorecido por el renacimiento de la actividad política y la consolidación de nuevas facciones. Tal optimismo, como en muchos otros casos de comienzo asociativo, facilitó un primer empuje al permitir a sus miembros evaluar positivamente la continuidad de la organización, y su capacidad futura para resarcirlos del esfuerzo y los recursos invertidos.

Como ha sido señalado, la Asociación Médica Bonaerense fue fundada en 1860 por un pequeño núcleo de jóvenes recién egresados de las aulas de la Facultad de Medicina. A la llamada de aquel grupo iniciador se adhirieron en forma inmediata varios profesores jóvenes con una posición más estable dentro de la Facultad de Medicina, y a petición de todos ellos, se incorporaron también figuras notables de la Facultad que arroparon a la naciente asociación con su prestigio ${ }^{13}$.

Durante sus primeros años de vida, de manera aproximada hasta 1867, y al igual que la otra sociedad existente, tuvo la Asociación Médica Bonaerense una vida lánguida y llena de dificultades que se limitó a la organización periódica de reuniones científicas, que no tuvieron el éxito esperado. Fueron frecuentes, en tal sentido, las críticas que recibió por sus escasas iniciativas y por lo poco concurridas que fueron sus reuniones. Los temores a la disolución parecen haber sido constantes durante estos primeros años ${ }^{14}$.

Resulta evidente entonces, que a su grupo inicial, que no excedía de veinte médicos, le resultaba extremadamente difícil lograr la adhesión de sectores más amplios de la profesión. Conspiraba contra ello la precariedad de los "otros" médicos como sector social y el escaso número de egresados de la Facultad.

12 Tales variables sociales son: educación, economía monetaria, estructura política y densidad organizativa previamente existente. STINCHCOMBE A. (1965), Social Structure and Organizations. En: MARCH, J., Handbook of organizations, New York. SARFATTI LARSON, M., (1979)

13 Consúltese "Asociación Médica Bonaerense", en $R M Q$ (1868), Año 5, n. 3, 8 de mayo, pp. 38-40.

14 Abundan las referencias a tal peligro. Así una nota retrospectiva señalaba que la sociedad en su primera época "ha tenido que luchar contra elementos de disolución" Ibidem. Consúltese también "Asociación Médica Bonaerense", en $R M Q$ (1870), año 7, n.16, 23 de noviembre, pp. 249-250. 
Por encima de todas aquellas dificultades, la Asociación Médica Bonaerense se vio minada en su afán aglutinador por la marcada heterogeneidad de los médicos como conjunto y, sobre todo, por las propias contradicciones de sus impulsores, quienes mientras hacían explícitos sus intentos de convertirla en representante de la totalidad del cuerpo médico, criticaban, a veces con inusitada dureza, a aquellos sectores médicos no integrados en su seno, lo que sin duda tendía a alejarlos.

Este alejamiento incrementaba a su vez las críticas y el despecho. Se subrayaba entonces el desinterés asociativo de muchos médicos y su preocupación exclusiva por las cuestiones materiales, a la vez que se los adjetivaba como "empíricos" llegándose en casos extremos a apelar a calificativos tales como "curanderos con patente" y "matasanos" 15 .

Sin duda, una fuerte dualidad producto de su ubicación subordinada, pero próxima a la élite, corroía al grupo impulsor de la Asociación Médica Bonaerense. Esto motivó que sus iniciativas oscilaran entre la aplicación de estrategias de solidaridad y cuestionamiento de las instituciones médicas y la recreación - más en sintonía con la élite-de mecanismos de exclusión frente a otros médicos, apartándolos así de los canales de acceso a las oportunidades y recursos ${ }^{16}$.

Si bien en el funcionamiento interno de la asociación tendieron a primar aquellas estrategias que la acercaban a la élite, sus tomas de posición en ese sentido, no estuvieron exentas de conflictos. Por ejemplo, la adhesión de autoridades de la Facultad de Medicina generó, desde un principio, importantes tensiones en el seno de la asociación y colocaba a sus impulsores en la difícil posición de tener que aceptar tal apoyo manteniendo a su vez una fisonomía propia, sobre todo si se tiene en cuenta que muchos de los jóvenes diplomados eran muy críticos con sus antiguos profesores y buscaban en la asociación un espacio más libre e independiente. Líneas internas divergentes se originaron por este motivo y su pugna llevó varias veces a la asociación al borde del colapso. Este fue evitado en 1864 al recurrirse al traslado del escenario de sus reuniones desde la Facultad de Medicina a la sala del Consejo de Higiene. Las argumentaciones esgrimidas en favor de tal cambio destacaron la importancia

$15 \mathrm{P}$. Mallo se refería a algunos colegas como "médicos retrógrados y adocenados que nada les hace merecer las simpatías y protecciones de las personas sensatas". $R M Q$ (1864), Año 1, $\mathrm{n}^{\circ} 10,23$ de agosto, p. 156. Son comunes también las críticas al materialismo de los médicos que no participan de la asociación, y que por lo tanto adoptaban esta "sólo como vehículo que conduce al dorado palacio de Plutón" Estas críticas llegaban a hacerse extensivas al conjunto del cuerpo médico, del que podía decirse que: "sólo hay en su seno, egoísmo, miseria, atraso". $R M Q$ (1864), Año 1, n 10, 23 de agosto, p. 156.

16 Se trató, en forma evidente, de un típico ejercicio ascendente del poder propio de un grupo subordinado tal cual es descrito por Parkin en sus hipótesis acerca de las estrategias de clausura dual. PARKIN F. (1974), Strategies of Social Closure in Class Formation. En: PARKIN, F. The Social Analysis of Class Structure, Tavistock, London. 


\section{RICARDO GONZÁLEZ LEANDRI}

de la "posesión de un campo neutral como punto de reunión" que limitara la influencia perniciosa de determinadas personalidades ${ }^{17}$.

Al concluir la década de 1860, el aumento del número de médicos jóvenes, y la mayor consistencia que comenzaron a adquirir como sector independiente, incidieron en la renovación de la Asociación Médica Bonaerense. Apoyándose en figuras de prestigio, pero que mantenían una cierta distancia con la élite de catedráticos, como Guillermo Rawson, modificó en 1868 su reglamento incrementando la heterogeneidad de sus fines y permitiendo que sus actividades cobraran mayor envergadura ${ }^{18}$. $\mathrm{Al}$ hacerse cargo de la redacción de la Revista Médico-Quirúrgica sus opiniones adquirieron también mayor trascendencia. Se vivieron a partir de entonces unos años de marcado optimismo y no es casual que desde ese momento comenzaran a publicarse comentarios sin duda fuertemente críticos con algunos aspectos del funcionamiento pasado de determinadas instituciones médicas.

Si bien a partir de entonces las reuniones de discusión científica continuaron siendo el eje del funcionamiento de la Asociación Médica Bonaerense, la defensa de "intereses profesionales" y los hechos relativos a la construcción de una "comunidad" comenzaron a hacerse no sólo más presentes sino también más precisos ${ }^{19}$.

Vinculada con aquellos cambios comenzó también a prevalecer una actitud nueva en su seno. Al sentirse más afianzados e independientes algunos de sus miembros proclamaron para la asociación el desarrollo de un nuevo papel frente a las instituciones estatales. Comenzaron por solicitar que fuera consultada con mayor frecuencia por el Gobierno Provincial y por la Municipalidad, "cuya Comisión de Higiene con honorables excepciones es formada por legos en estas materias sin más rudimentos de la ciencia que los vulgares", pero fue al Gobierno Nacional al que se dirigieron con más énfasis sugiriendo "¿por qué no eleva y protege el Gobierno Nacional a la Asociación Médica Bonaerense elevándola al rango de Academia Medical?"20.

De las críticas vertidas sobre los organismos a los que se pretendía reemplazar "sin espíritu de cuerpo y poco versados en el estudio y aplicaciones de cuestiones higiénicas, médico-administrativas y médico-legales" puede deducirse cuáles eran según los peticionantes las virtudes que encumbraban a la Asociación Médica Bonaerense y que la ubicaban en un lugar privilegiado para ejercer funciones vinculadas al Estado. El hecho de que la posesión de un "espíritu de cuerpo", más allá de su existencia real, fuera destacado a partir de entonces como un elemento relevante es un síntoma de la importancia del cambio cualitativo que comenzaba a gestarse en el seno de la Asociación Médico Bonaerense y en un sector más amplio de médicos.

\footnotetext{
$17 R M Q$ (1864), Año $1, \mathrm{n}^{\circ} 5,8$ de junio, p.67

$18 R M Q$ (1868), Año 5, $\mathrm{n}^{\circ}$ 2, 23 de abril, pp.18-19.

19 Véase por ejemplo"Nuestros propósitos", en $R M Q$ (1869), Año 6, no 1, 8 de abril, p.4.

20 "Revista de la Quincena", en $R M Q$ (1869), Año 5, n 22, 23 de febrero, pp. 345-346.
} 


\section{La Sociedad Médico-Práctica}

Además de la Asociación Médica Bonaerense existieron durante este periodo otras dos asociaciones, la Sociedad Médico-Práctica y la Sociedad de Estudios Químicos.

La Sociedad Médico-Práctica parece haber tenido características similares a la Asociación Médica Bonaerense, aunque poco se sabe en realidad de su funcionamiento ${ }^{21}$. Su vida fue efímera y puede considerarse como el primer intento frustrado de asociacionismo médico. Muchos de sus miembros lo eran a su vez de la Asociación Médica Bonaerense aunque su vínculo con la élite de la profesión y con sus instituciones parece haber sido más firme. De hecho, Montes de Oca, como presidente de la Facultad, era su dirigente máximo.

Según referencias dispersas publicadas en la prensa médica no parece que la Sociedad Médico-Práctica haya logrado operar de manera continua en algún momento. En su deterioro y posterior ocaso influyeron de forma decisiva las disensiones políticas que surgieron entre sus dirigentes, hecho, por otra parte, muy frecuente en la época. En 1865 Nicolás Albarellos hacía referencia a su escaso éxito, que atribuía a las disputas desagradables que se desarrollaban en su seno, y que lo llevó a expresar la necesidad de "anteponer la ciencia a los intereses personales"22. Años más tarde, en una nota de carácter retrospectivo, se señalaba que "la Sociedad Médico-Práctica ha muerto por egoísmo"23. Su funcionamiento intermitente no parece haber superado los años 1864 ó 1865 .

\section{La Sociedad de Estudios Químicos}

Esta sociedad se acercó más al modelo de learned society. Fundada en 1864, no pasó de la reunión de conocidos en una casa particular, a pesar del esfuerzo de sus miembros por darle un carácter más institucional ${ }^{24}$. Representó un intento interesante de amalgamar a un conjunto heterogéneo de profesionales médicos, químicos y farmacéuticos, hecho muy poco frecuente en una época caracterizada más por las tensiones y los esfuerzos por delimitar áreas de incumbencias precisas que por los intentos de colaboración. Es más, podría agregarse que, si bien la presencia de médicos fue importante y el impulso inicial obedeció a uno de ellos, la Asociación de Estudios Químicos no fue una asociación específicamente médica y que hay que destacar de ella la hegemonía reconocida de otros sectores. De hecho la primer presidencia le fue conferida al profesor Puiggari, químico y farmacéutico.

\footnotetext{
$21 R M Q$ (1864), Año $1, \mathrm{n}^{\circ} 3,8$ de mayo, p. 31.

$22 R M Q$ (1865), Año 2, n. 14, 23 de octubre, pp. 219-220.

23 "Nuestros propósitos", en $(R M Q), 1869$, Año 6, n $^{\circ} 1,8$ de abril, p. 3.

24 "Nueva asociación de estudios químicos", en $R M Q$ (1865), año 1, n.23, 8 de marzo. p. 414.
} 


\section{RICARDO GONZÁLEZ LEANDRI}

Puede decirse, en tal sentido, que la sociedad fue tributaria de las ideas de su impulsor, Angel Gallardo, que abogaban en general por la inclusión y el consenso entre los sectores diplomados que se ocupaban de distintos aspectos del arte de curar.

Que la Sociedad de Estudios Químicos funcionara con tales características pone de manifiesto la existencia de proyectos alternativos dentro del vasto entramado del arte de curar. Su vida efímera indica, también, la precariedad de los proyectos asociativos que tuvieron como principales impulsores a los "otros" médicos durante este período.

\section{LA DECADA DE 1870.}

1. El ocaso de la Sociedad Médica Bonaerense y el surgimiento de otros polos institucionales autónomos.

Durante el trascurso de la década de 1870, y después de superar la ciudad la epidemia de fiebre amarilla de 1871, que determinó una seria parálisis económica y de las actividades del Estado, comenzó a gestarse de manera gradual una percepción bastante generalizada de que el conjunto de la sociedad estaba siendo sometida a importantes transformaciones. Si bien los notables altibajos no permitían, a muchos, hacerse una idea definida acerca de la dirección real de dichos cambios, el progreso comercial, las inversiones y, sobre todo, las cifras de inmigración despertaban el optimismo.

Comenzaba una era de progreso ${ }^{25}$. Este, sin embargo, emergía entremezclado con un cúmulo de problemas políticos y sociales que causaban cierta incertidumbre en los contemporáneos. La prensa periódica se hacía eco de aquellos problemas y consideraba que los médicos tenían un importante papel que jugar en algunos de ellos, como los flagelos epidemicos, de cólera y de fiebre amarilla, que cada vez con mayor frecuencia asolaban la región. Una crónica de la época, por ejemplo, expresaba que: "Los tiempos de prueba parecen haber terminado, dando nacimiento a una nueva era, en la cual el desarrollo del progreso bajo todas sus manifestaciones nos colocará en el nivel que debemos ocupar entre los pueblos grandes y civilizados de la tierra", para agregar a continuación, y refiriéndose a los acuciantes problemas políticos y sanitarios: "Desgraciadamente, todas las esperanzas legítimas que ella hace concebir pueden venir a estrellarse en algunos obstáculos que la Providencia, la imprevisión o la imprudencia, pueden colocar en nuestro camino"26.

25 GASIO, G. y SAN ROMÁN C. (1977), La Conquista del progreso, 1874-1880, La Bastilla, Buenos Aires, y (1980), "La Presidencia de Avellaneda". En Gallo E. y FERrARI, G. Argentina del 80 al Centenario, Sudamericana, Buenos Aires.

26 "El progreso del país", en La Prensa, (1873), 21 de diciembre. 
Curiosamente, algunos periodistas y políticos comenzaron también a referirse a la existencia de una cuestión social, pero no dotaban al tema de la especificidad que adquiriría años más tarde, incluso en boca de aquellos que de manera enfática negaban su existencia. Las pugnas facciosas entre élites políticas rivales era el tema que, al igual que en la década anterior, ocupaba de manera omnipresente la esfera pública. Esto condujo a un comentarista a expresar que, "cuando los partidos llegan al grado de exaltación en que se encuentran los nuestros, la pasión política domina todas las consideraciones" 27 .

En lo que atañe a nuestro tema específico, varias fueron las cuestiones que adquirieron una importante presencia pública y ayudaron a la consolidación de ese clima social de progreso e incertidumbre. Se trató de una época de reformas impulsadas en buena medida por el Estado Provincial y precedidas por tumultos y cuestionamientos. La antigua élite de la facultad empezó a ver cómo a su lado comenzaban a surgir sectores que, teóricamente subordinados, comenzaban a cuestionar su papel hegemónico. La más importante de aquellas reformas fue la creación de la nueva Facultad de Ciencias Médicas, el remozamiento de sus planes de estudio y su incorporación al seno de la Universidad de Buenos Aires. Al mismo tiempo la dirección de la Facultad, y del cuerpo médico todo, se encomendó a una recién creada Academia de Medicina. Ello fue producto de la negociación entre el Estado, que demandaba disciplina interna a los médicos, la vieja élite y ciertos miembros destacados de las cohortes de aspirantes a incluirse en su seno como Wilde y Mattos. Como telón de fondo de estas negociaciones se situaban las fuertes impugnaciones de los estudiantes, y de su líder José María Ramos Mejía, que emergían como un nuevo agente social e indirectamente también político ${ }^{28}$.

Las reformas introducidas tanto en el seno de la Facultad de Medicina como en la Universidad en su conjunto fueron consideradas como más formales que reales por muchos contemporáneos, por lo que la tensión y las discusiones y conflictos promovidos por los estudiantes y por sectores desplazados continuaron durante el resto de la década. El epicentro de las tensiones estuvo situado en la Facultad de Derecho, pero la Facultad de Medicina también se vio seriamente influida por los mismos acontecimientos. No es de extrañar entonces que la cuestión disciplinaria fuera el tema de debate predominante en los claustros de las distintas facultades, llegando a preocupar de manera importante al propio gobierno 29 .

Pero el impulso social de la época era, sin duda, también muy fuerte, por lo que comenzaron también a generarse espacios de nuevo cuño. Comenzó a despuntar un

27 "Las listas de diputados", en La Prensa, (1873), 28 de diciembre.

28 CANTÓN, E. (1928); HALPERÍN DONGHI, T. (1966); QUIROGA M. (1972), Historia de la Academia de Medicina de Buenos Aires, Buenos Aires; GonZÁlEZ LEANDRI, R. (1977), “Académicos, Doctores y aspirantes", Entrepasados, 12.

29 HALPERIN DONGHI, T. (1966); GONZÁLEZ LEANDRI, R. (1977). 


\section{RICARDO GONZÁLEZ LEANDRI}

clima científico y a tono con ese desarrollo, se escuchó con mayor asiduidad a aquellos que se definían a si mismos como "hombres prácticos" y que estaban a favor de la promoción de nuevas disciplinas académicas a las que trataban de vincularse en forma creciente siguiendo el ejemplo del ex rector Gutierrez ${ }^{30}$.

Una de las cuestiones más características de este nuevo clima que surgía era la crítica a las que se consideraba "carreras tradicionales". Comenzaba a cuestionarse con renovada contundencia - y cierto grado de exageración - el hecho de que los argentinos nativos quisieran convertirse todos en "doctores", dejando la práctica del comercio y la industria en manos de inmigrantes extranjeros. Esto, a su vez, se combinaba con la apreciación de que se avecinaba de manera inminente una época de exceso de doctores, idea de la cual se hicieron eco, y de manera notable, las propias autoridades provinciales. Algunos iban mas allá, y culpaban a tal exceso de abogados y médicos de ser la causa determinante de la virulencia que registraban las pugnas facciosas en esos momentos. Se pensaba que los doctores "sin clientela y sin pacientes" se hallaban siempre disponibles para actuar como clientelas políticas e incorporarse - y promover-a las disputas de carácter político ${ }^{31}$.

Si bien esta mentalidad de hombres prácticos no llegó a cuajar de una manera predominante en los ámbitos institucionales sí se hizo sentir de forma crucial en la opinión durante este período ${ }^{32}$. En cuanto a las "carreras liberales", Derecho y Medi-

\footnotetext{
30 La Prensa daba cuenta de ese nuevo clima y expresaba que: "La juventud empieza a empeñarse en estudios científicos que eran hasta ahora el patrimonio exclusivo de los extranjeros que han derramado en este país sus conocimientos", "Cuestiones de interés científico", en La Prensa, (1877), 28 de marzo. La novedad más importante generada por ese nuevo movimiento fue la creación de la Sociedad Científica Argentina en cuya instauración jugó un papel relevante la Sociedad de Farmacia Argentina. Sus inicios no estuvieron, sin embargo, exentos de tensiones. El proyecto fue, sin duda, ambicioso e intentó nuclear en una misma institución y en un mismo edificio, a todas las asociaciones existentes. Sin embargo, chocó contra la negativa de los respectivos cuerpos profesionales. Sus primeras reuniones fueron tensas, y desde la Revista Farmacéutica se criticó severamente que estuviera constituida fundamentalmente por abogados y por personajes relevantes del mundo político como Leandro $\mathrm{N}$. Alem, quienes pretendían cerrar el paso a químicos y naturalistas y a miembros de otras carreras no tradicionales. Véase "Concurso científico- V $V^{\circ}$ Aniversario de la Sociedad Científica", en La Prensa, (1877), 5 de abril.

31 "Decadencia moral", en La Prensa, (1876), 5 de agosto. "El movimiento intelectual", en idem, (1877), 1 de marzo. En estos artículos se constataba que la juventud se hallaba concentrada sólo en ciertas carreras y se vaticinaba el advenimiento de una época de conflictos. A su vez el órgano de expresión del Círculo Médico mostraba su preocupación por los intentos de cerrar el acceso a la enseñanza superior y su presidente contestaba a las quejas del gobernador de la Provincia acerca de la abundancia de "doctores sin clientela y sin pacientes" con la siguiente expresión "Nosotros haremos médicos que no formarán clientela pero que por lo mismo se verán obligados a hacer la ciencia", "Movimiento de la Asociación", en Anales del Círculo Medico Argentino, (1879), año 2, nº 5, pp. 399-405.

32 Políticos notorios abogaron de manera relevante por esa transformación. Se destacó, en tal sentido, la figura de Sarmiento. BOTANA N., (1984), La tradición republicana, ed. Sudamericana, Buenos Aires; HALPERIN DONGHI, T. (1980), Proyecto y construcción de una nación, ed. Ayacucho, Caracas; TEDESCO J. (1982), Educación y sociedad en Argentina, CEAL, Buenos Aires.
} 
cina, esto trajo aparejado un importante, a la vez que inesperado, cuestionamiento de aspectos vinculados a su organización interna y a sus expectativas más amplias.

La evolución interna de la Asociación Médica Bonaerense se vio influida seriamente por los avatares sociales y por el clima de ideas de la época, entre otras cosas por la participación de algunos de sus miembros en una primera línea. De tal manera, en el preciso momento en que parecía estar entrando en una etapa de consolidación plena comenzó, sin embargo, a caer en un irreparable declive que la condujo a su desmembramiento al final de la década de 1870 . De nada sirvieron, por lo tanto, los recurrentes intentos de hacerla resurgir. La promoción de una parte de sus miembros más activos a la categoría de académicos, además de significar un revés para algunos aspectos organizativos, no fue bien recibida por algunos colegas, por lo que las tensiones y los distanciamientos en su seno se hicieron cada vez más importantes. Las incidencias con respecto al control de su órgano de prensa fueron un claro exponente de esa nueva situación, en el momento mismo en que estaba siendo creada la Academia de Medicina. En esos años, distintos observadores señalaban ya que la Asociación había prácticamente dejado de existir como tal ${ }^{33}$.

Un interesante acontecimiento, promovido en gran parte por una cuestión ajena al cuerpo médico local y de alto valor simbólico, condujo a su resurgimiento y a la realización de intentos más serios, aunque también efímeros, de otorgarle un nuevo rumbo. Hallándose en ese estado de existencia sólo nominal, la Asociación Médica Bonaerense recibió en enero de 1876 una invitación para enviar un representante al Congreso médico internacional que se celebraría en Filadelfia, con motivo del centenario de la independencia de Estados Unidos. La difusión de esa noticia promovió los más diversos comentarios dentro y fuera del cuerpo médico. Se la consideraba una oportunidad inmejorable de otorgar a la profesión, y con ella al país todo, una presencia internacional que no se podía desaprovechar. La postura de La Prensa fue, en la ocasión, característica: "La Sociedad Médica de Buenos Aires ha recibido también su invitación. Disuelta como está nada ha podido ni podrá hacer. Y, sin embargo, es necesario, es casi forzoso que se responda a aquella invitación para que la República Argentina pueda hacer oir su voz en aquel torneo universal de la ciencia"34. Y agregaba una cuestión de enorme trascendencia en muchos aspectos: tal concurrencia era necesaria para dejar "los intereses y el nombre argentino en una posición espectable". Dicho periódico, que había mantenido hasta entonces una relación histórica muy estrecha con los médicos, se permitía finalmente sugerirles y, en cierta medida, apremiarlos: "¿Por qué ha de renunciar el cuerpo médico a su representación en el gran Congreso de Filadelfia? Reúnanse los médicos de Buenos Aires, cambien y organicen sus ideas y nombren representantes que, por su elevada inteli-

33 ConI. E. (1918), Memorias de un médico Higienista, Imprenta Coni,, Buenos Aires.

34 "Congreso Internacional de Medicina", en La Prensa, (1876), 28 de enero. 


\section{RICARDO GONZÁLEZ LEANDRI}

gencia y contracción al estudio, dejen un rastro luminoso en las sesiones del Congreso Universal de Medicina. Por nuestra parte levantamos desde ya la candidatura del Dr. Guillermo Rawson"35.

Así se hizo finalmente y, como era de esperarse, el Dr. Rawson fue nombrado representante de la Asociación Médica Bonaerense para participar en lo que se consideraba un evento de magnitud para la evolución del cuerpo médico argentino. Tal decisión promovió, sin embargo, un debate en el seno de la Academia de Medicina recientemente creada dado que algunos de sus miembros consideraban que era la propia Academia, en su carácter de órgano institucional supremo de la profesión, quien debía emitir autorizaciones y enviar representantes. Otra postura hacía hincapié, en cambio, en que la que había recibido dicha misiva era la Asociación Médica Bonaerense, y no la Academia. No se sabe, a ciencia cierta, qué resolvió finalmente esta institución, aunque puede resaltarse, en tal sentido, que en las actas del Congreso de Filadelfia, Rawson estaba inscrito como representante de la Asociación Médica Bonaerense, y lo que es más, toda su correspondencia, que con gran pompa publicaba la prensa diaria, estaba dirigida sólo al Gobierno y a dicha sociedad ${ }^{36}$.

Los avatares promovidos por la invitación al Congreso Internacional de Filadelfia pusieron en evidencia varias cuestiones de importancia. En primer lugar, se hicieron más claras aún las diferencias de carácter personal, pero fundamentalmente institucionales, que dividían a la élite de la profesión médica, sobre todo a partir de la creación de la Academia. En segundo término, tal acontecimiento planteaba un tema de gran trascendencia para el destino profesional de la corporación médica como conjunto. La celebración cada vez más frecuente de congresos médicos internacionales es indicativo de que la Medicina entraba a jugar, de manera cada vez más importante, como un factor generador de prestigio corporativo y, sobre todo, nacional. No es extraño entonces que, como elemento simbólico de primera magnitud, fuera colocada en un espacio relevante en la competencia y la pugna por el predominio entre nacionalidades rivales, en especial por parte de Alemania y Francia, en unos marcos crecientemente internacionalizados ${ }^{37}$. Sin quererlo casi, y a pesar de mirar siempre, y de forma necesaria, en aquella dirección, los médicos argentinos comenzaban a verse incluidos también en esos marcos que excedían sus propias fronteras. Este hecho,

\footnotetext{
35 Ibidem.

36 Eliseo Cantón hace referencia a la reunión de la Academia y al problema de incumbencias planteado. Sin embargo, erróneamente, sitúa a Rawson como delegado de la Facultad de Medicina. Tanto la ponencia presentada por Rawson, como su correspondencia posterior a la Asociación Médica Bonaerense fueron publicadas por La Prensa, muchas de ellas en primera plana. Consúltese"El Doctor Rawson en el Congreso Médico Internacional", en La Prensa (1876), 15, 16, 17 y 19 de diciembre y "El Congreso Médico reunido en Filadelfia", en La Prensa (1877), 25 de marzo.

37 Un interesante indicio de tal situación fue que al Congreso de Filadelfia, organizado por un país al que se consideraba de segundo orden en cuestiones médicas, no asistió ningún representante de Alemania ni de Francia, países situados a la cabeza de su evolución.
} 
sobre todo por los ribetes de carácter simbólico con que se veía recubierto, tuvo para los médicos un efecto legitimador de primera magnitud ante las autoridades gubernamentales locales. La emotiva despedida brindada a Rawson en el puerto de Buenos Aires por colegas y estudiantes, que en gran número se hicieron allí presentes, considerada por la prensa como un acto que excedía el mero marco profesional, es indicativa de que los médicos estaban dando un enorme paso en el camino de su legitimidad. Pero, al mismo tiempo, las cartas dirigidas en forma solemne por Rawson desde Estados Unidos al presidente de una asociación, que todo el mundo sabía que sólo vivía en su nombre, ponían también de manifiesto las fuertes contradicciones que aquejaban a los médicos como cuerpo, y como profesión, a nivel local.

Después de estos acontecimientos de importante carácter público, la asociación siguió existiendo de manera nominal, aunque seguramente inducida por ellos, comenzó a dar muestras de cierta actividad a partir de septiembre de ese mismo año. En sus primeras reuniones se procedió a aceptar la renuncia indeclinable presentada por su secretario y a modificar el reglamento interno. Por otra parte, y por lo que puede inferirse de un breve extracto de sus debates publicados por la Revista MédicoQuirúrgica, algunos de sus miembros dejaron traslucir la intención de dar un renovado impulso y publicidad a sus actividades. Salvo la presencia de Mallo, infatigable defensor de las actividades asociativas, y de unos pocos médicos con importante actividad pública previa como Mattos, el resto de los participantes era obvio que pertenecían a nuevas promociones. Los académicos estaban ausentes en su casi totalidad ${ }^{38}$.

Las intenciones mostradas en aquellas reuniones no se vieron, sin embargo, traducidas en hechos concretos y las siguientes registraron un tono alicaído y una escasa participación. Poco más se sabe de las actividades desarrolladas por la Asociación Médica durante ese año y el siguiente, salvo que renovó su comisión directiva a principios de 1877 y que, según un breve comentario de Coni, estaba saliendo de la inacción en que se encontraba "de una manera bastante eficaz" 39 . A los pocos meses, las actividades de la asociación volvieron al que había sido su estado natural en los últimos años, lo que forzó a la Revista Médico-Quirúrgica a cambiar de opinión y a "deplorar nuevamente que este centro de reunión que forman la mayor parte de los médicos distinguidos del país y extranjeros establecidos en esta ciudad haya vuelto a caer en su proverbial apatía" 40 . Al explayarse en sus consideraciones el redactor de la revista expuso sus propios argumentos acerca del porqué del fracaso de la asociación. Este se debía, según Coni, a las "rivalidades mezquinas" existentes entre los médicos y a que muchos "posponen al interés de la profesión y de la ganancia de

\footnotetext{
38 "Asociación Médica Bonaerense", en $R M Q$ (1876), año 13, n. 11, 8 de septiembre, pp. 266-267 y "Asociación Médica Bonaerense", en $R M Q$ (1876), año 13, n. 13, 8 de octubre pp. 314-315..

39 “Asociación Médica Bonaerense. Proyecto de Concurso para 1878", en $R M Q$ (1877), año 14, n. 12, septiembre 23, pp.268-269.

40 “Asociación Médica Bonaerense", en $R M Q$ (1878), año 14, n. 19, 8 de enero pp. 439-440.
} 
clientes los sentimientos más altos que deben ligar a miembros de una sociedad o gremio científico cuyo interés bien entendido debía estar en la buena armonía entre sí’"

Argumentos similares fueron esgrimidos por Herrera Vegas, nombrado nuevo presidente, al intentar, una vez más, levantar el alicaído espíritu predominante entre los médicos que la conformaban: "En resumen señores: es un deber para nosotros el fomentar el espíritu de asociación, para nadie tan necesario como para los médicos; de esto sacaremos ventajas materiales, científicas y principalmente sociales"42. Como se ve, volvía a hacerse necesario, al igual que en la década anterior, enfatizar, una y otra vez, las ventajas del asociacionismo, que el grueso de los médicos, tanto de la élite como de su periferia próxima, no parecía ver tan claro.

Sin embargo, durante la presidencia de Herrera Vegas, la actividad de la asociación mostró cierta mejora. Ello se debió en gran parte a que se promovió un importante debate acerca del control epidémico y de la vigencia de las cuarentenas. El éxito de tales reuniones y la difusión de los artículos por ellas promovidos, que ocuparon un importante espacio en las páginas de la Revista Médico-Quirúrgica, son un claro indicio de cuales eran las cuestiones que lograban movilizar en forma predominante las inquietudes de los médicos ${ }^{43}$. En tal sentido, el discurso pronunciado por Herrera Vegas en 1879 con motivo de la finalización de su presidencia destacaba cómo la sociedad se había preocupado en dicho año "preferentemente de cuestiones de higiene pública, que por su importancia y aplicación práctica al país contribuían a dar a la Asociación cierto prestigio del que hasta hoy había carecido" 44 . Se auguraba una nueva época de mejoras y para apuntalarla se nombró como nuevo presidente a Guillermo Rawson, que había regresado ya de su periplo estadounidense y europeo arropado por un prestigio considerable ${ }^{45}$.

Sin embargo, tales augurios no se cumplieron y la Asociación Médica Bonaerense continuó su lenta agonía. Había nacido veinte años atrás como representante de los "otros médicos" y conoció hacia fines de la década de 1860 unos breves momentos de esplendor, cuando jóvenes como Wilde, Golfarini y Mallo, bajo la protección de Rawson, habían querido establecer una cierta autonomía de las instancias oficiales. Sin embargo, fue poco a poco perdiendo fuerza e iniciativa debido a las

\footnotetext{
41 Ibidem.

42 "Asociación Médica Bonaerense. Discurso del Dr. Herrera Vegas al recibirse de la presidencia", en $R M Q$ (1878), año 15, n. 3, 8 de mayo, pp. 65-66.

43 Los debates en los que intervinieron los doctores Hirón, Ledesma y Mallo se encuentran transcritos en: "La importancia de las cuarentenas. Memoria presentada a la Asociación Médica Bonaerense por el Dr. Hirón”, en $R M Q$ (1878), año 15, n. 8, 23 de julio, pp. 191-194 y n. 9, 8 de agosto, pp. 205-212. "Importancia de las cuarentenas. Memoria leída en la sesión del 1 de agosto en la Asociación Médica Bonaerense", en $R M Q$ (1878), año 15, n. 10, 23 de agosto, pp. 229-239 y n. 11, 8 de septiembre, pp. 248-254 y "Argumentos contra las cuarentenas", en idem. pp. 254-260 y en n.12, 23 de septiembre, pp. 278-283.

44 “Asociación Médica Bonaerense", en $R M Q$ (1879), año 16, n.2, 23 de abril, p. 27.

45 Ibidem.
} 
crecientes divisiones en su seno y a una cierta incapacidad de incorporar a las nuevas promociones de médicos que surgían. Su bandera sería retomada por otra institución, el Círculo Médico Argentino, que revalorizó, sobre todo, el carácter impugnador de sus primeros tiempos. De tal forma el presidente del nuevo núcleo asociativo evaluaba en una de sus primeras manifestaciones públicas el destino de la Asociación Médica, a la que consideraba producto de una generación: "La Sociedad Médica Bonaerense fundada por ellos hace algunos años ha fracasado por falta de cooperación de parte de sus asociados, ha muerto de inanición y no hace mucho que algunos de sus miembros trataron de galvanizar ese cadáver, que no ha respondido por cierto a las débiles excitaciones comunicadas con tan loable objeto"46.

Para el logro de sus objetivos de autonomía, el Círculo Médico Argentino, que se definía como novedoso y más heterogéneo, debió apelar a mecanismos que si bien no lo diferenciaban de manera absoluta de la experiencia previa de la Asociación Médica Bonaerense, sí implicaban otorgar mayor énfasis a la construcción asociativa y a la impugnación de las instancias oficiales.

De aquel afán de conformar un espacio propio se derivaron sus críticas a las actividades de la Academia, sus campañas por la implantación del modelo médicoinstitucional alemán y de la enseñanza libre y, posteriormente, la organización de eventos de alto contenido simbólico, como el funeral cívico de Darwin.

La Academia, por su parte, apuntalada como estaba por unos gobiernos que hacían de su protección una cuestión de estado, pudo superar los trances conflictivos que le presentaban estos incipientes polos médicos alternativos. Sin embargo, su papel de productora y objetivadora legítima y monopólica de la verdad científica y, por lo tanto, de abanderada primordial del progreso, comenzaba a serle disputado, como nunca antes, de una manera organizada y a la vez institucional.

Si bien la Asociación Médica Bonaerense desapareció practicamente al ser creada la Academia, y el Círculo Médico, heredero de los impulsos más fuertemente impugnadores de principios de la década, no llegó a consolidarse en forma plena como institución alternativa durante este período, sí abrieron, en cambio, un rumbo que sería retomado pocos años más tarde, junto a sus banderas, por unos nuevos sectores sociales medios que, si bien ya estaban presentes en la escena, lo estaban de una manera todavía balbuceante.

46 Idem. p. 15 